\title{
Anti-angiogenic action of plasma hyaluronan binding protein in human umbilical vein endothelial cells
}

\author{
JI WON JEON ${ }^{1,2^{*}}$, HYUN SEOK SONG ${ }^{2 *}$, EUN-JOUNG MOON ${ }^{1}$, SHI-YOUNG PARK ${ }^{1}$, \\ MYUNG JIN SON ${ }^{2}$, SEUNG YOUN JUNG ${ }^{1}$, JI TAE KIM ${ }^{1}$, DO-HYUN NAM ${ }^{2,5}$, \\ NAM-HO CHOI-MIURA ${ }^{3}$, KYU-WON KIM ${ }^{4}$ and YUNG-JIN KIM ${ }^{1}$
}

\begin{abstract}
${ }^{1}$ Department of Molecular Biology, Pusan National University, Busan 609-735; ${ }^{2}$ Department of Neurosurgery, Samsung Medical Center and Samsung Biomedical Research Institute, Sung Kyun Kwan University School of Medicine, Seoul 135-710, South Korea; ${ }^{3}$ Department of Physiological Chemistry, School of Pharmaceutical Science, Showa University, Tokyo 142-8555, Japan; ${ }^{4}$ Research Institute of Pharmaceutical Sciences, College of Pharmacy, Seoul National University, Seoul 151-742; ${ }^{5}$ Xenotransplantation Research Center, Seoul, South Korea
\end{abstract}

Received December 27, 2005; Accepted February 21, 2006

\begin{abstract}
The kringle domain is a triple loop structure present in angiostatin and endostatin. The disulfide bond-linked kringle architectures have been known to be essential for anti-angiogenic activity. Plasma hyaluronan binding protein (PHBP) is a novel serine protease which consists of three epidermal growth factor (EGF) domains, a kringle domain, and a serine protease domain. PHBP can be cleaved autocatalytically to generate activity and is highly expressed in the human blood and liver. To determine the anti-angiogenic activities of PHBP, we purified recombinant mouse PHBP from stable cell line overexpressing PHBP and used protein in vivo and in vitro angiogenesis assays. We found that recombinant $\mathrm{PHBP}$ inhibits not only angiogenesis in vivo in chorioallantoic membrane (CAM) assay but also the basic fibroblast growth factor (bFGF)-induced proliferation, invasion and tube formation of human umbilical vein endothelial cells (HUVECs) in a dose-dependant manner. Moreover, we found that the kringle domain of PHBP was essential for the antiangiogenic action of PHBP by the deletion mutants. These
\end{abstract}

Correspondence to: Dr Yung-Jin Kim, Department of Molecular Biology, Pusan National University, Busan 609-735, South Korea E-mail: yjinkim@pusan.ac.kr

Dr Kyu-Won Kim, Research Institute of Pharmaceutical Sciences, College of Pharmacy, Seoul National University, Seoul 151-742, South Korea

E-mail: qwonkim@plaza.snu.ac.kr

${ }^{*}$ Contributed equally

Abbreviations: CAM, chorioallantoic membrane; PHBP, plasma hyaluronan binding protein; bFGF, basic fibroblast growth factor; VEGF, vascular endothelial growth factor

Key words: angiogenesis inhibition, plasma hyaluronan binding protein, factor VII activating protease findings unravel a new function of PHBP as an inhibitor of the proangiogenic phenotype of vascular endothelial cells and demonstrate that the kringle domain of PHBP might be a potent novel inhibitor of activated endothelial cells in vitro and in vivo.

\section{Introduction}

Angiogenesis, the sprouting of new capillaries from preexisting vasculature, is an essential physiological process in embryonic development, wound healing, and reproductive cycles in adult females (1). It is also recognized as a characteristic of pathological conditions such as psoriasis, proliferative retinopathies, and cancer growth and metastasis (2). During angiogenesis, endothelial cells need to divide, migrate, invade the extracellular matrix, and form capillary structures from pre-existing blood vessels (3). These complex processes imply the presence of multiple controls, which can be temporarily turned on and off within a short period $(4,5)$. A switch of the angiogenic phenotype by an up-regulation of angiogenesis activators and down-regulation of angiogenesis inhibitors often leads to the progression of many diseases $(1,6,7)$.

An endogenous angiogenesis inhibitor, angiostatin, is an internal fragment of plasminogen and contains the first three or four triple loop structures, known as kringle domains (8). The primary amino acid sequence of each kringle domain is composed of approximately 80 amino acids and the structure exists in many proteins. The disulfide bond-linked kringle architectures are essential for the anti-angiogenic activity of angiostatin (9). A previous study shows that kringle fragments of several other proteins also inhibit angiogenesis (8). Most kringles only inhibit angiogenesis when cleaved as fragments from their parental proteins that lack anti-angiogenic activity.

PHBP, isolated by adsorption to immobilized hyaluronan, is a novel glycoprotein found in human plasma. The domain structure of PHBP is composed of one secretion signal peptide, three epidermal growth factor (EGF) domains, one kringle domain and one serine protease domain from its amino-terminus (10). PHBP has the ability of the protease to 
activate coagulation factor VII (FVII), named FVII-activating protease (FSAP) $(11,12)$, and to activate tissue- or urinaryplasminogen activators $(11,17)$.

Single-chain PHBP is a $70-k D a$ zymogen that exists in human plasma at a concentration of $12 \mu \mathrm{g} / \mathrm{ml}$ and can be cleaved autocatalytically to generate the active two-chain form $(50 \mathrm{kDa}$ and $27 \mathrm{kDa})$ linked by a disulfide bond $(13,14)$. PHBP exhibits a strong affinity for negatively charged substances such as hyaluronic acid, dextran sulfate, or heparin, all of which enhance autoactivation. At a cellular level, PHBP interacts with glycosaminoglycans (GAGs) and directly cleaves matrix proteins such as fibronectin, and fibrinogen $(17,18)$. In addition, PHBP specifically binds to vascular smooth muscle cells and reduces platelet-derived growth factor (PDGF)-dependent smooth muscle cell proliferation. The complex formation between PHBP and PDGF has been reported as the major cause (16).

Recently, it has been reported that PHBP inhibits bFGF/ EGF-induced proliferation of HUVECs (18). The authors present two possible mechanisms involved. First, PHBP cleaves adhesion molecules which are required for attachment and proliferation. Second, PHBP strongly binds to and partially hydrolyses bFGF. However, even though PHBP affects the proliferation of endothelial cells, the precise mechanisms of PHBP on the process of angiogenesis were not elucidated. Therefore, more detailed studies are required to determine the effects of PHBP on the process of angiogenesis.

In order to determine whether PHBP containing kringle domain can be a novel angiogenesis inhibitor, we performed in vivo and in vitro angiogenesis assays using recombinant mouse PHBP.

\section{Materials and methods}

Cell culture. HUVECs were grown on $0.3 \%$ gelatin-coated dishes and maintained in endothelial cell growth medium EGM-2 kit (Clonetics, San Diego, CA). HUVECs were used at passage from 2 to 8. Human embryonic kidney (HEK) 293 cells were cultured in Dulbecco's modified Eagle's medium (DMEM) supplemented with heat-inactivated $10 \%$ fetal bovine serum (FBS), 100 units/ml penicillin and $100 \mu \mathrm{g} / \mathrm{ml}$ streptomycin. Cells were grown in a $37^{\circ} \mathrm{C}$ incubator with a humidified atmosphere containing $5 \% \mathrm{CO}_{2}, 95 \%$ air.

Construction of the expression vector. The E. coli expression vector (pBluescript, Stratagene) of full-length mouse PHBP cDNA was obtained from Dr N.-H. Choi-Miura (Showa University, Japan).

To examine the effects of PHBP on angiogenesis, fulllength mouse PHBP cDNA was constructed with the mammalian expression vector, pcDNA3.1/V5-His-TOPO (Invitrogen, Grand Island, NY). The complete open reading frame of PHBP cDNA was produced by PCR from E. coli expression vector. The following primers were used: forward, GAGATGTTTGTCAGGATGTTG; and downstream, GAG GCCAGCCTCCCTGT.

Expression and purification of recombinant mouse PHBP. Constructed plasmid DNA was introduced into HEK293 cells using Lipofectamine and Plus reagents (Invitrogen,
Carlsbad, CA) and selected in DMEM with 10\% FBS and $400 \mu \mathrm{g} / \mathrm{ml} \mathrm{G} 418$. The stable cell line was incubated with DMEM containing $1 \%$ FBS, and then the conditioned medium was harvested and analyzed by sodium dodecyl sulfatepolyacrylamide gel electrophoresis (SDS-PAGE) and immunoblotting with anti-V5 antibody (Invitrogen, Carlsbad, CA). Recombinant mouse PHBP from conditioned medium was concentrated using Vivaspin concentrator (Sartorius, Hannover, Germany), purified using Ni-NTA magnetic agarose beads (Qiagen, Valencia, CA) under native conditions, according to the manufacturer's instructions.

Chorioallantoic membrane (CAM) assay. To determine the anti-angiogenic activity of recombinant mouse PHBP in vivo, a CAM assay was performed as previously described $(21,22)$. Fertilized eggs (Pulmuone, Kyungki-do, Korea) were incubated at $37^{\circ} \mathrm{C}$ and $90 \%$ relative humidity. After 3 days, approximately 2-3 $\mathrm{ml}$ of albumin was removed and a window was made. At the 4.5-day-old CAM, test samples or retinoic acid $(1 \mu \mathrm{g})$ loaded on a quarter size of Thermanox coverslip (Nunc International, Naperville, IL) were applied on the CAM of individual embryos. After 48-h incubation, $10 \%$ fat emulsion (Intralipose; Korea Green Cross, Seoul, Korea) was injected into the CAM for observation of the inhibition zone of angiogenesis under a microscope.

$\left[{ }^{3} \mathrm{H}\right]$-thymidine incorporation assay. To examine the antiproliferative effect of PHBP, HUVECs were seeded at a density of $2 \times 10^{4}$ cells/well in a 24 -well plate. Cells were incubated in EGM and allowed to attach for $24 \mathrm{~h}$. Cells were washed two times with endothelial basal medium (EBM) and incubated for $6 \mathrm{~h}$ in EBM containing 1\% FBS. Cells were stimulated by the addition of the indicated concentration of PHBP and $25 \mathrm{ng} / \mathrm{ml}$ of bFGF (Upstate, Lake Placid, NY) for $24 \mathrm{~h}$, and were subjected for $4 \mathrm{~h}$ to the addition of $1 \mu \mathrm{Ci} / \mathrm{ml}\left[{ }^{3} \mathrm{H}\right]-$ thymidine (Amersham Pharmacia Biotechnology, Piscataway, NJ). After fixing cells with methanol, high molecular mass $\left[{ }^{3} \mathrm{H}\right]$-radioactivity was precipitated using $5 \%$ trichloroacetic acid at $4^{\circ} \mathrm{C}$ for $16 \mathrm{~h}$. After two washes with PBS, $\left[{ }^{3} \mathrm{H}\right]$ radioactivity was solubilized in $0.2 \mathrm{~N} \mathrm{NaOH}$ and $0.1 \%$ SDS and determined using a liquid scintillation counter (Beckman Instruments, Fullerton, CA). Each experiment was performed in triplicate.

Invasion assay. The invasive chemotactic motility of HUVECs was assayed using a Transwell chamber with 6.5-mm diameter polycarbonate filters $(8-\mu \mathrm{m}$ pore size, Corning Costar, NY, USA). Briefly, the lower surface of the filter was coated with $10 \mu \mathrm{g}$ of gelatin, and the upper surface of the filter was coated with $10 \mu \mathrm{g}$ of Matrigel (BD Biosciences, Bedford, MA). The indicated concentration of PHBP and bFGF $(25 \mathrm{ng} / \mathrm{ml})$ prepared in $600 \mu \mathrm{l}$ of EBM with $1 \%$ FBS and $0.1 \%$ BSA were placed in the lower side. HUVECs were trypsinized and suspended at a final concentration of $5 \times 10^{5}$ cells $/ \mathrm{ml}$ in EBM containing $1 \%$ FBS. Cell suspension $(100 \mu 1)$ was loaded into each of the upper wells. The chamber was incubated at $37^{\circ} \mathrm{C}$ for 16-20 h. Cells were fixed in methanol and stained with hematoxylin and eosin. Non-migrating cells on the upper surface of the filter were removed by wiping with a cotton swab, and invasive cells were quantified by counting the 
A



Figure 1. Expression and purification of mouse recombinant PHBP from human embryonic kidney 293 cells. Mouse PHBP cDNA was in-frame cloned into pcDNA3.1/V5-His-TOPO, transfected into HEK293 cells, and selected by G418. Conditioned medium was harvested from HEK293 cells and analyzed by SDS-PAGE on $10 \%$ gel under reducing conditions. (A) The gel was stained with Coomassie blue. (B) Western blotting was performed with anti-V5 antibody. Lane 1, total protein of conditioned medium; lane 2, sample eluted from conditioned medium using the Ni-NTA magnetic agarose beads.

cells that migrated to the lower side of the filter using optical microscopy.

Tube formation assay. Matrigel $(10 \mathrm{mg} / \mathrm{ml})$ was loaded in a 24-well plate and polymerized for $30 \mathrm{~min}$ at $37^{\circ} \mathrm{C}$. HUVECs incubated in EBM with $1 \%$ FBS for $6 \mathrm{~h}$ were harvested after trypsin treatment, resuspended in EBM with $1 \% \mathrm{FBS}$, plated onto a layer of Matrigel at a density of $4 \times 10^{5}$ cells/well, and followed by the addition of PHBP. Matrigel cultures were incubated at $37^{\circ} \mathrm{C}$. After 12 or $24 \mathrm{~h}$, the cultures were photographed ( $\mathrm{x} 40$ magnification). The area covered by the tube network was photographed.

Western blotting. Cells were lysed with ice-cold lysis buffer [150 mM NaCl, 10 mM Tris-HCl (pH 7.4), 1 mM EDTA, 0.5\% NP-40 and $1 \%$ Triton X-100] containing $1 \mathrm{mM} \mathrm{Na}_{3} \mathrm{VO}_{4}$, $0.2 \mathrm{mM}$ phenylmethylsulfonyl fluoride (PMSF) and protease inhibitor cocktail (Sigma). Conditioned medium from HEK293 were also obtained with $0.2 \mathrm{mM}$ PMSF and protease inhibitor cocktail. Protein was quantitated using the BCA method with bovine serum albumin (BSA) as standard, and separated by SDS-PAGE, and electroblotted to a polyvinyldifluoride (PVDF) membrane. The membrane was blocked for $2 \mathrm{~h}$ at room temperature in PBS-T and 5\% non-fat dry milk, and then incubated with primary antibody for $2 \mathrm{~h}$ at room temperature. After washing with PBS-Tween-20, the membrane was incubated with secondary antibody for $1 \mathrm{~h}$ and visualized using ECL reagents according to the manufacturer's instructions.

Construction of the truncated plasmids of PHBP. To examine whether the kringle domain of PHBP is responsible for the anti-angiogenic effects of PHBP, 3'-end truncated mutants of PHBP cDNA were constructed with pcDNA3.1/V5-His-TOPO. One removed only the serine protease domain (termed $\Delta \mathrm{S}$ ) and the other removed both the kringle and serine protease domain (termed $\triangle K S$ ). $\Delta S$ and $\triangle K S$ were produced by PCR from wild-type PHBP expression vector, pcDNA3.1/PHBP-V5-His wild-type. The following primers were used: for $\Delta S$, forward ATGTTTGTCAGGATGTTGTGTTT and reverse ACGCT TGACTGCGTGTTCAGCT; for $\triangle \mathrm{KS}$, forward ATGTTTGT CAGGATGTTGTGTTT and reverse GTCGTCCGGACCTA TTTCACAG.

Data analysis and statistics. All data shown are as means \pm SD or as percentage of control, and representative data from one of three replicate experiments are shown. Statistical comparisons between groups were performed using the Student's t-test. Data were considered statistically significant at $\mathrm{P}<0.05$.

\section{Results}

Expression and purification of recombinant mouse PHBP protein from human embryonic kidney 293 cells. To examine the effects of PHBP on the angiogenesis of endothelial cells induced by bFGF, full-length mouse PHBP cDNA was constructed. The cDNA encoding mouse PHBP protein was in-frame cloned into pcDNA3.1/V5-His-TOPO, and then the vector was transfected into HEK293 cells. The expression of mouse PHBP protein of the conditioned medium was verified by Coomassie blue staining and Western blot analysis (Fig. 1A and $\mathrm{B}$, lane 1 , respectively). Purified recombinant mouse PHBP using Ni-NTA magnetic agarose beads was detected in lane 2. Single-chain PHBP $(70 \mathrm{kDa})$ and light chain of active two-chain form PHBP (30 kDa) were observed by Western blot analysis with anti-V5 antibody under reducing conditions (Fig. 1B).

PHBP inhibits angiogenesis on chick CAM. The antiangiogenic activity of PHBP was investigated in the chick in vivo CAM assay, which is a useful model to investigate the effect of compounds on basal angiogenesis (23). Purified PHBP, added to the CAM, significantly inhibited the formation of blood vessels in a dose-dependent manner (Fig. 2). At the
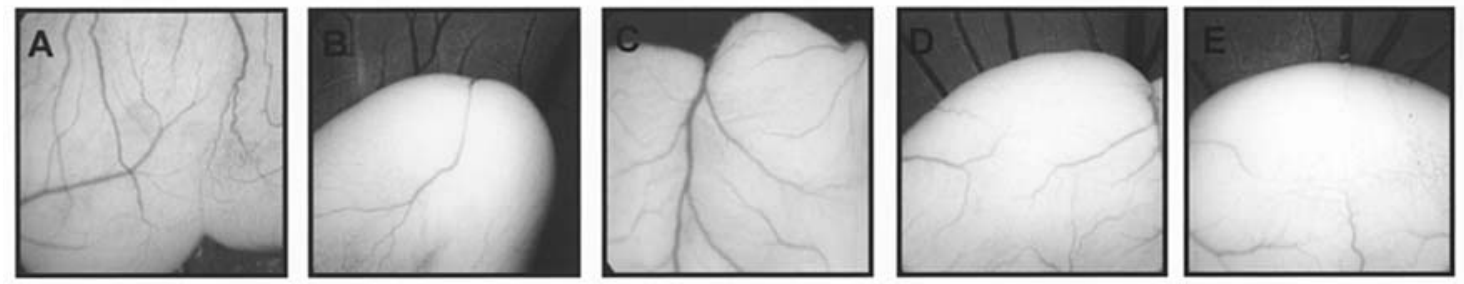

Figure 2. PHBP inhibits angiogenesis on chick CAM. Thermanox coverslips containing variable amounts of PHBP were applied to the CAMs of 4.5-day-old chick embryos. After $48 \mathrm{~h}$ of incubation, $10 \%$ fat emulsion (Intralipose) was injected into the CAM for observation of the inhibition zone of angiogenesis under a microscope. (A) Control; (B) retinoic acid ( $1 \mu \mathrm{g} /$ disc), positive control; (C) $0.1 \mu \mathrm{g} /$ disc of PHBP; (D) $1 \mu \mathrm{g} / \mathrm{disc}$ of PHBP; (E) $10 \mu \mathrm{g} /$ disc of PHBP. 
Table I. Anti-angiogenic effect of PHBP on the chick CAM.

\begin{tabular}{lcccc}
\hline Compounds & $\begin{array}{c}\text { Dose } \\
(\mu \mathrm{g} / \mathrm{egg})\end{array}$ & $\begin{array}{c}\text { Eggs showing } \\
\text { angiogenesis } \\
\text { inhibition }\end{array}$ & $\begin{array}{c}\text { Total } \\
\text { eggs } \\
\text { tested }\end{array}$ & $\begin{array}{c}\% \text { of } \\
\text { inhibition } \\
(\text { mean } \pm \mathrm{SD})\end{array}$ \\
\hline Control $^{\mathrm{a}}$ & - & 2 & 12 & $16.7 \pm 4.7$ \\
Retinoic acid $^{\mathrm{a}}$ & 1 & 9 & 13 & $69.2 \pm 12.8^{\mathrm{b}}$ \\
PHBP & 0.1 & 6 & 22 & $27.3 \pm 5.7^{\mathrm{b}}$ \\
& 1 & 11 & 21 & $52.4 \pm 13.1^{\mathrm{b}}$ \\
& 10 & 13 & 14 & $92.9 \pm 23.2^{\mathrm{b}}$ \\
\hline
\end{tabular}

Anti-angiogenic responses were scored as positive when the PHBPtreated CAM showed an avascular zone similar to retinoic acidtreated CAM, which had a afew vessels compared with control, and were calculated by the percentage of positive eggs. ${ }^{b} \mathrm{P}<0.05$ versus control.

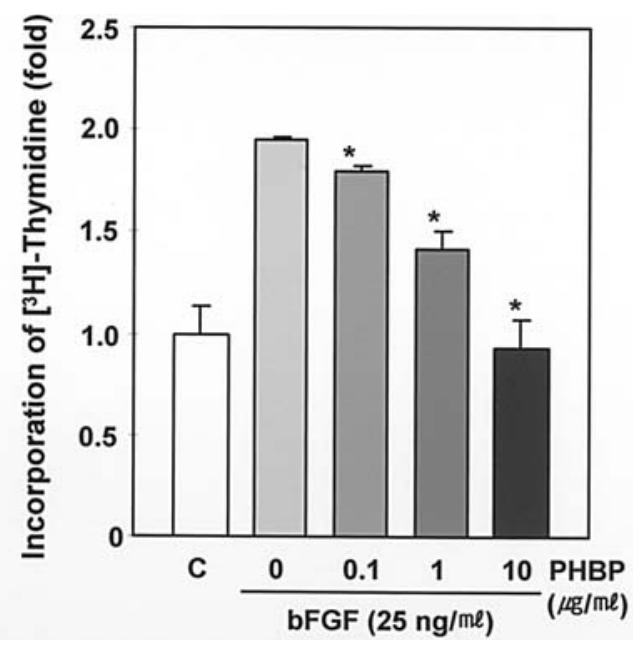

Figure 3. PHBP inhibits bFGF-induced HUVEC DNA synthesis. The indicated concentrations of PHBP were added to HUVECs stimulated with bFGF $(25 \mathrm{ng} / \mathrm{ml})$ and incubated for $24 \mathrm{~h} .\left[{ }^{3} \mathrm{H}\right]$-thymidine was presented during the last $4 \mathrm{~h}$ of incubation. Data represent the means $\pm \mathrm{SD}$ of triplicate, and similar results were obtained in at least three different experiments. C, untreated control cells. ${ }^{*} \mathrm{P}<0.05$ versus $\mathrm{bFGF}$ alone.

maximum concentration (10 $\mu \mathrm{g} /$ disc), PHBP inhibited angiogenesis at $92.9 \%$ of the treated embryos (Table I). This finding indicates that PHBP prevents angiogenesis in vivo, affecting spontaneous angiogenesis of the embryo. The normal structure of the other components of the CAM, such as the chorionic and allantoic epithelia, was not affected, suggesting a selective effect of PHBP on the vascular structures.

PHBP inhibits bFGF-induced HUVEC proliferation. The process of angiogenesis requires endothelial cell proliferation, extracellular matrix degradation and invasion through the underlying basement membrane and interstitial matrix and, finally, spatial organization to form a network of new vessels (24). Therefore, we investigated whether PHBP could affect endothelial cell functions relevant to angiogenesis in vitro. Since kringle structure affected endothelial cell growth on angiogenesis (8), we verified the anti-proliferative effect of



Figure 4. PHBP inhibits bFGF-induced HUVEC invasion. The indicated amounts of PHBP were placed in the lower side of Transwell with bFGF $(25 \mathrm{ng} / \mathrm{ml})$ in EBM containing 1\% FBS. Data represent the means \pm SD of duplicate, and similar results were obtained in at least three different experiments. $\mathrm{C}$, untreated control cells. ${ }^{*} \mathrm{P}<0.05$ versus bFGF alone.

PHBP on HUVECs using $\left[{ }^{3} \mathrm{H}\right]$-thymidine incorporation assay. PHBP inhibited the DNA synthesis of HUVECs in a dosedependent manner (Fig. 3). PHBP at $10 \mu \mathrm{g} / \mathrm{ml}$ inhibited entirely bFGF-induced HUVEC proliferation. The proliferation of HUVECs induced by vascular endothelial growth factor (VEGF) was also inhibited in a dose-dependent manner (data not shown).

PHBP inhibits bFGF-induced HUVEC invasion. To examine whether PHBP regulates endothelial cell invasion, the ability of HUVECs to penetrate the reconstituted basement membrane, Matrigel, was assessed. PHBP decreased the invasion of HUVECs in a dose-dependent manner (Fig. 4). The result was obtained when PHBP had been added to the lower side of the Transwell, but a dose-dependent addition of PHBP to the upper side of the Transwell did not inhibit the invasion of HUVECs (data not shown). These data suggest that interaction of PHBP and bFGF is important to inhibit the invasion of HUVECs.

PHBP inhibits bFGF-induced HUVEC tube formation. To determine whether PHBP has an inhibitory effect on the tube formation of endothelial cells, the effect of PHBP on the alignment of endothelial cells in capillary-like structures was evaluated (Fig. 5). HUVECs were plated onto a thick layer of Matrigel where they rapidly aligned forming tubes. These tubes became stronger and more robust with longer networks as time of treatment with bFGF progressed. In contrast, the presence of PHBP caused a concentration-dependent inhibition of bFGF-induced tube formation. PHBP at $10 \mu \mathrm{g} / \mathrm{ml}$ inhibited the network formation of HUVECs, resulting in less extensive, broken, foreshortened, and much thinner vessels at many sites.

The kringle domain of PHBP is essential to inhibit bFGFinduced HUVEC tube formation. To determine which domain of PHBP is responsible for the inhibitory effect on angiogenesis, mutant forms of PHBP, $\Delta S$ (serine protease domaindeleted form of PHBP) and $\triangle \mathrm{KS}$ (both kringle and serine 



Figure 5. PHBP inhibits bFGF-induced tube formation of HUVECs. HUVECs were treated with various concentrations of PHBP and plated onto a thick layer of pre-coated Matrigel $(10 \mathrm{mg} / \mathrm{ml})$ in a 24-well plate. The morphological changes of HUVECs in the surface of Matrigel were investigated. Images were taken $12 \mathrm{~h}$ after plating (x40 magnification). (A) Control; (B) bFGF (25 ng/ml); (C) bFGF + $0.1 \mu \mathrm{g} / \mathrm{ml}$ of PHBP; (D) bFGF $+1 \mu \mathrm{g} / \mathrm{ml}$ of PHBP; (E) bFGF + $10 \mu \mathrm{g} / \mathrm{ml}$ of PHBP.

A

\begin{tabular}{|c|c|}
\hline PHBPwt & $\mathrm{K}$ \\
\hline $\mathrm{PHBP} \triangle \mathrm{S}$ & s \\
\hline \multirow[t]{2}{*}{$\mathrm{PHBP} \triangle \mathrm{KS}$} & $E$ \\
\hline & $\begin{array}{l}\text { S: Signal peptide } \\
\text { E: EGF1,2,3 } \\
\text { K: Kringle } \\
\text { P: Serine protease }\end{array}$ \\
\hline
\end{tabular}

C

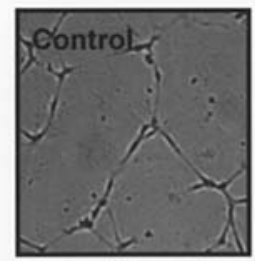



B
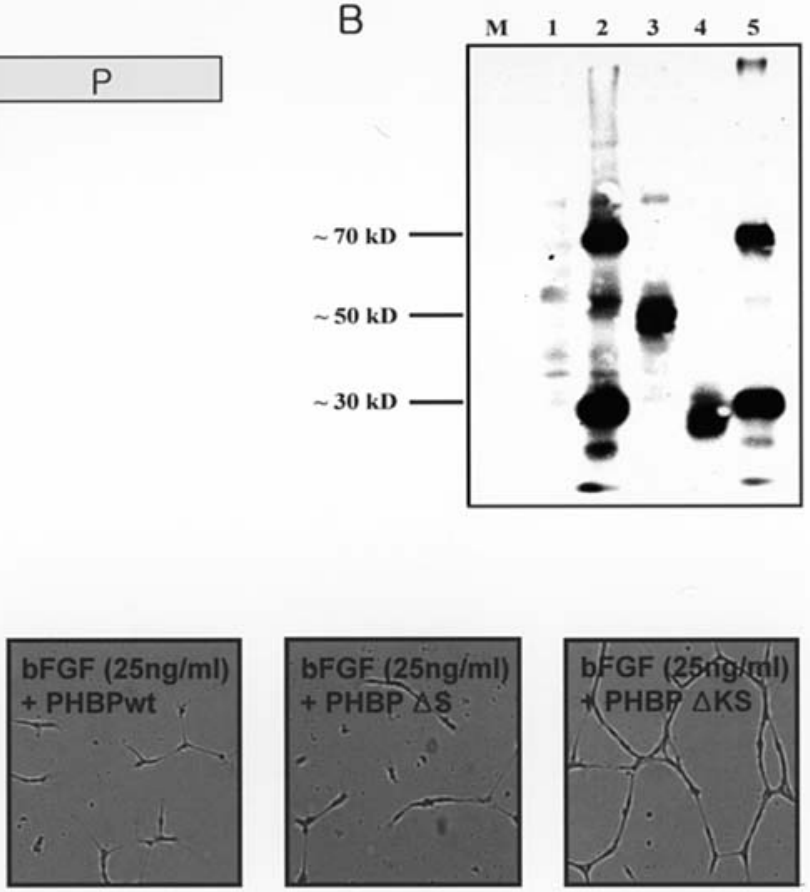

Figure 6. The kringle domain of PHBP is essential to inhibit bFGF-induced tube formation of HUVECs. (A) PHBP $\triangle \mathrm{S}$ was a deleted serine protease domain from C-terminus of PHBP. PHBP $\triangle \mathrm{KS}$ was a deleted kringle domain and a serine protease domain from C-terminus of PHBP, only three EGF domains of PHBP remained. (B) Conditioned medium was harvested from HEK293 cells and analyzed by SDS-PAGE on 10\% gel under reducing conditions. Western blotting was performed with anti-V5 antibody. Lane 1, untransfected; lane 2, wild-type PHBP; lane 3, $\Delta \mathrm{S}$; lane 4, $\Delta K S$; lane 5 , stable transfectants of wildtype PHBP. (C) The kringle domain of PHBP is essential to inhibit bFGF-induced tube formation of HUVECs. Images were taken $24 \mathrm{~h}$ after plating (x40 magnification). Similar results were obtained in two different experiments.

protease domain-deleted form) were constructed (Fig. 6A). The expression of $\Delta \mathrm{S}(\sim 50 \mathrm{kDa})$ and $\Delta \mathrm{KS}(\sim 30 \mathrm{kDa})$ on the conditioned media of HEK293 cells were verified by Western blot analysis (Fig. 6B). The overexpression of $\Delta S$, the serine protease domain-deleted form of PHBP, effectively inhibited bFGF-induced tube formation on HUVECs and its antiangiogenic effect was similar to that shown by the treatment of wild-type PHBP. However, the $\triangle K S$-treated HUVECs failed to form a blood vessel network (Fig. 6C).

\section{Discussion}

In order to identify novel angiogenesis inhibitors, we searched proteins containing a kringle domain by using a gene screening method with structural basis and focused on PHBP.

PHBP is known as a regulator in hemostasis, which is a tissue factor-independent activator of factor VII promoting early steps of the coagulation pathway (12), and contributes to the fibrinolytic pathway by activating plasminogen activator (25). In addition to the roles described above, it is possible that PHBP has another function on endothelial cells, since PHBP is abundantly present in human plasma and contains a kringle domain within its structure. Therefore, this study was conducted to gain insights into the cellular effects of PHBP on vascular endothelial cells.

As a function independent of the role of PHBP in the hemostatic system, we clearly elucidated the possible role(s) of PHBP in angiogenesis by performing in vivo and in vitro angiogenesis assays. We first tested the effect of PHBP on angiogenesis in chick embryo and then observed that PHBP significantly inhibits the development of capillary networks in CAM (Fig. 2).

We next observed the effects of PHBP on angiogenesis in each step by using in vitro angiogenesis assays, since the 
angiogenic process is a tightly regulated phenomenon that includes sequential steps. PHBP markedly inhibited bFGFinduced proliferation (Fig. 3) and invasion (Fig. 4) of HUVECs in a dose-dependent manner. It is noted that both bFGF-induced proliferation and invasion of HUVECs were completely inhibited by treatment of $10 \mu \mathrm{g} / \mathrm{ml}$ PHBP.

To determine the effect of PHBP on HUVEC differentiation, we conducted a tube formation assay. In the presence of bFGF, HUVECs, placed on the Matrigel, established a tube-like structure that seemed to be indicative of an early stage of angiogenic development, whereas HUVECs in the presence of PHBP hardly formed capillary-like networks (Fig. 5).

In addition, we also found that anti-angiogenic activities of PHBP do not seem to depend on the specificity of growth factor. PHBP efficiently prevents the proliferation, invasion and tube formation of HUVECs induced by bFGF or VEGF in a dose-dependent manner (Fig. 3; unpublished data). This is consistent with the most recent study that PHBP inhibits bFGF/EGF-induced proliferation of HUVECs (18).

Collectively, our findings that PHBP blocked endothelial cell proliferation, invasion and tube formation in vitro suggest that PHBP acts at a multi-step process of the angiogenic cascade, and might explain its potent anti-angiogenic activity in vivo. Especially, the angiostatic activities of PHBP were validated at a concentration of $10 \mu \mathrm{g} / \mathrm{ml}$, which is close to the amount of PHBP under physiological conditions $(12 \mu \mathrm{g} / \mathrm{ml})$. These results provide evidence that the physiological role of PHBP is not restricted to hemostasis but also affects angiogenesis.

PHBP contains a kringle domain which shares some homology with the kringles of plasminogen. Kringle domains are independent structural and functional folding units found in several proteins involved in blood coagulation and fibrinolysis (8). A series of studies show that hemostasis and angiogenesis are increasingly interrelated. During vessel repair, the regulation of angiogenesis is mediated by proteins secreted by the hemostatic system, which include cryptic fragments from the coagulation cascade and fibrinolytic system.

Kringles 1-4 (angiostatin) or kringle 5 of plasminogen are known for their anti-angiogenic activity by selectively inhibiting endothelial cell growth (26). In addition, kringles derived from other molecules such as kringle 2 of prothrombin and kringles of human hepatocyte growth factor were also found to be inhibitors of endothelial cell proliferation $(27,28)$.

Therefore, we speculate that the anti-angiogenic properties of PHBP may be mediated by kringle structure and investigated whether the kringle domain is essential to the anti-angiogenic activity of PHBP. We performed tube formation assay with two kinds of mutants, $\Delta S$ (serine protease domain-deleted form of PHBP) and $\triangle \mathrm{KS}$ (both kringle and serine protease domain-deleted form) (Fig. 6). We found that the serine protease domain of PHBP was not necessary to the antiangiogenic effect. However, the serine protease and kringle domain-truncated mutant was deprived of the anti-angiogenic ability of PHBP. This result indicates that the kringle domain of PHBP is essential to the anti-angiogenic activity of PHBP.

We demonstrate the structural and functional relationships of the kringle domain of PHBP in the regulation of angiogenesis. However, the molecular mechanisms of the anti-angiogenic action of PHBP still need to be defined. Although PHBP exists at a high concentration in human plasma, PHBP might not exert the inhibitory effect of angiogenesis under normal physiological conditions. Consequently, it might play an important role in maintaining the angiostatic condition. In physiological and pathological conditions, such as wound healing or tumor progression, PHBP may be activated and then inhibit angiogenesis through inhibiting endothelial functions and interfering with angiogenic signalings.

Our results indicate that PHBP potently inhibits multiple angiogenic processes in vitro and in vivo, and that these antiangiogenic actions of PHBP are mediated by the kringle structure, a conserved architecture that specifically inhibits angiogenesis.

\section{Acknowledgements}

This study was supported by a grant from Korea Research Foundation Grant (KRF 2002-041-C00219).

\section{References}

1. Carmeliet $\mathrm{P}$ and Jain RK: Angiogenesis in cancer and other diseases. Nature 407: 249-257, 2000.

2. Hanahan D and Folkman J: Patterns and emerging mechanisms of the angiogenic switch during tumorigenesis. Cell 86: 353-364, 1996.

3. Bussolino F, Mantovani A and Persico G: Molecular mechanisms of blood vessel formation. Trends Biochem Sci 22: 251-256, 1997

4. O'Reilly MS, Boehm T, Shing Y, Fukai N, Vasios G, Lane WS, Olsen BR and Folkman J: Endostatin: an endogenous inhibitor of angiogenesis and tumor growth. Cell 88: 277-285, 1997.

5. Bergers G, Javaherian K, Lo KM, Folkman J and Hanahan D: Effects of angiogenesis inhibitors on multistage carcinogenesis in mice. Science 284: 808-812, 1999.

6. Folkman J: Angiogenesis in cancer, vascular, rheumatoid and other disease. Nat Med 1: 27-31, 1995.

7. Pugh CW and Ratcliffe PJ: Regulation of angiogenesis by hypoxia: role of the HIF system. Nat Med 9: 677-684, 2003.

8. Cao Y, Cao R and Veitonmaki N: Kringle structures and antiangiogenesis. Curr Med Chem Anti-Cancer Agents 2: 667-681, 2002.

9. O'Reilly MS, Holmgren L, Shing Y, Chen C, Rosenthal RA, Moses M, Lane WS, Cao Y, Sage EH and Folkman J: Angiostatin: a novel angiogenesis inhibitor that mediates the suppression of metastases by a Lewis lung carcinoma. Cell 79: 315-328, 1994.

10. Choi-Miura NH, Tobe T, Sumiya J, Nakano Y, Sano Y, Mazda T and Tomita M: Purification and characterization of a novel hyaluronan-binding protein (PHBP) from human plasma: it has three EGF, a kringle and a serine protease domain, similar to hepatocyte growth factor activator. J Biochem 119: 1157-1165, 1996.

11. Kannemeier C, Feussner A, Stohr HA, Weisse J, Preissner KT and Romisch J: Factor VII and single-chain plasminogen activator-activating protease: activation and autoactivation of the proenzyme. Eur J Biochem 268: 3789-3796, 2001.

12. Romisch J, Feussner A, Vermohlen S and Stohr HA: A protease isolated from human plasma activating factor VII independent of tissue factor. Blood Coagul Fibrinolysis 10: 471-479, 1999.

13. Sumiya J, Asakawa S, Tobe T, Hashimoto K, Saguchi K, Choi-Miura NH, Shimizu Y, Minoshima S, Shimizu N and Tomita M: Isolation and characterization of the plasma hyaluronan-binding protein (PHBP) gene (HABP2). J Biochem 122: 983-990, 1997

14. Romisch J, Feussner A and Stohr HA: Quantitation of the factor VII- and single-chain plasminogen activator-activating protease in plasmas of healthy subjects. Blood Coagul Fibrinolysis 12: 375-383, 2001.

15. Choi-Miura NH, Saito K, Takahashi K, Yoda M and Tomita M: Regulation mechanism of the serine protease activity of plasma hyaluronan binding protein. Biol Pharm Bull 24: 221-225, 2001. 
16. Kannemeier C, Al-Fakhri N, Preissner KT and Kanse SM: Factor VII-activating protease (FSAP) inhibits growth factormediated cell proliferation and migration of vascular smooth muscle cells. FASEB J 18: 728-730, 2004.

17. Choi-Miura NH, Yoda M, Saito K, Takahashi K and Tomita M: Identification of the substrates for plasma hyaluronan binding protein. Biol Pharm Bull 24: 140-143, 2001.

18. Etscheid M, Beer N, Kress JA, Seitz R and Dodt J: Inhibition of $\mathrm{bFGF/EGF-dependent} \mathrm{endothelial} \mathrm{cell} \mathrm{proliferation} \mathrm{by} \mathrm{the}$ hyaluronan-binding protease from human plasma. Eur J Cell Biol 82: 597-604, 2004.

19. Choi-Miura NH, Takahashi K, Yoda M, Saito K, Mazda T and Tomita M: Proteolytic activation and inactivation of the serine protease activity of plasma hyaluronan binding protein. Biol Pharm Bull 24: 448-452, 2001.

20. Kisker O, Onizuka S, Banyard J, Komiyama T, Becker CM, Achilles EG, Barnes CM, O'Reilly MS, Folkman J and PirieShepherd SR: Generation of multiple angiogenesis inhibitors by human pancreatic cancer. Cancer Res 61: 7298-7304, 2001.

21. Nguyen M, Shing Y and Folkman J: Quantitation of angiogenesis and antiangiogenesis in the chick embryo chorioallantoic membrane. Microvasc Res 47: 31-40, 1994.

22. Hahm ER, Gho YS, Park S, Park C, Kim KW and Yang CH: Synthetic curcumin analogs inhibit activator protein-1 transcription and tumor-induced angiogenesis. Biochem Biophys Res Commun 321: 337-344, 2004.
23. Ribatti D, Nico B, Vacca A, Roncali L, Burri PH and Djonov V: Chorioallantoic membrane capillary bed: a useful target for studying angiogenesis and anti-angiogenesis in vivo. Anat Rec 264: 317-324, 2001

24. Taraboletti G, Poli M, Dossi R, Manenti L, Borsotti P, Faircloth GT, Broggini M, D'Incalci M, Ribatti D and Giavazzi R: Antiangiogenic activity of aplidine, a new agent of marine origin. Br J Cancer 90: 2418-2424, 2004.

25. Romisch J, Vermohlen S, Feussner A and Stohr H: The FVII activating protease cleaves single-chain plasminogen activators. Haemostasis 29: 292-299, 1999.

26. Cao Y, Ji RW, Davidson D, Schaller J, Marti D, Sohndel S, McCance SG, O'Reilly MS, Llinas M and Folkman J: Kringle domains of human angiostatin. Characterization of the antiproliferative activity on endothelial cells. J Biol Chem 271: 29461-29467, 1996.

27. Kuba K, Matsumoto K, Date K, Shimura H, Tanaka M and Nakamura T: HGF/NK4, a four-kringle antagonist of hepatocyte growth factor, is an angiogenesis inhibitor that suppresses tumor growth and metastasis in mice. Cancer Res 60: 6737-6743, 2000.

28. Kim KS, Hong YK, Joe YA, Lee Y, Shin JY, Park HE, Lee IH, Lee SY, Kang DK, Chang SI and Chung SI: Anti-angiogenic activity of the recombinant kringle domain of urokinase and its specific entry into endothelial cells. J Biol Chem 278: 11449-11456, 2003. 